ISSN: $2036-5438$

\title{
A New Form of Democratic Oversight in the EU: The Joint Parliamentary Scrutiny Group for Europol \\ by \\ Ian Cooper*
}

Perspectives on Federalism, Vol. 10, issue 3, 2018 


\section{Abstract}

In 2017, a new Joint Parliamentary Scrutiny Group (JPSG) was created to enable members of the national parliaments of the EU and the European Parliament to exercise joint oversight of the EU agency for police cooperation (Europol). This paper chronicles and explains the lengthy legal and political process leading up to the first meeting of the Europol JPSG in October 2017, and the establishment of its Rules of Procedure at its second meeting in March 2018. In addition, the Europol JPSG is compared to the three EU inter-parliamentary conferences (IPCs) which meet twice-yearly to discuss EU affairs, foreign policy and economic governance. While there are many similarities, the JPSG differs from these others in that it has an explicit mandate to scrutinize, and the target of its scrutiny is a specific EU agency rather than a whole policy field. The JPSG is also distinctive in a number of key respects, including a stronger legal basis, more restrictive membership and participation rules, greater continuity of membership, stronger access to EU officials and documents, a seat on the Europol Management Board and an explicit right to ask oral and written questions. Taken together, these attributes indicate that the JPSG is designed to be an oversight body, rather than merely a discussion forum. Finally, the paper considers the likely future UK role in relation to the Europol JPSG after Brexit.

\section{Key-words}

European Union, Europol, Inter-Parliamentary Conferences, Joint Parliamentary Scrutiny Group, Parliamentary Scrutiny 


\section{Introduction}

The Joint Parliamentary Scrutiny Group (JPSG) was created in 2017 to exercise oversight over the European Police Agency (Europol). It is the first of its kind, insofar as it is an interparliamentary body made up of members of the European Parliament (EP) and the national parliaments of the European Union (EU), with a legal mandate to scrutinize the activities of an EU agency. These attributes set it apart from the other EU interparliamentary bodies with a comparatively weaker legal mandate and a broader field of policy concern. It is also a unique arrangement in comparison to other EU agencies, which do not enjoy treaty recognition and are subject to weak oversight from the EP and individual national parliaments but not joint scrutiny from both.

The key question of this paper, particularly in the context of this special issue, is whether the JPSG for Europol represents a new form of democratic oversight in the EU. More specifically, is it essentially similar to or qualitatively different from other forms of interparliamentary cooperation in the EU, in particular the three major Inter-Parliamentary Conferences (IPCs) - the COSAC Plenary, the CFSP-CSDP Conference and the SECG Conference. Early scholarly analysis is of varying opinion as to whether the JPSG 'represents a major step forward for interparliamentary scrutiny' (Kreilinger 2017: 15) or that 'it is to be expected that Europol does not have to fear direct consequences of this parliamentary scrutiny' (Gless and Wahl 2017: 353). Suspecting that the JPSG may be merely 'old wine in new bottles,' one observer noted that 'it may not be as different from the pre-existing interparliamentary conferences as one could have expected' (Fromage 2017).

Certainly, the Europol JPSG shares structural similarities with the three IPCs. The author has previously argued that the three IPCs share three attributes - they are EU-specific (in membership and policy focus), large (involving multiple participants from each parliament) and permanent (meeting twice-yearly rather than on an ad hoc basis) - which set them apart from other forms of inter-parliamentary cooperation such as the NATO Parliamentary Assembly (which is not EU-specific), the EU Speakers Conference (which is small) or Inter-Parliamentary Committee Meetings (which are ad hoc) (Cooper 2019 (forthcoming)). By this measure, the Europol JPSG belongs in the same category of 
institution as the IPCs: its membership is comprised of EU parliaments meeting to discuss EU-related issues, it is large (albeit somewhat smaller than the three IPCs), and it meets on a regular, twice-yearly basis. However, a close examination of the Europol JPSG reveals a number of key differences from the three IPCs, all of which attest to the fact that it is explicitly mandated and designed not as a talking shop but as a scrutiny body. Taken together, these make the Europol JPSG different in kind from the IPCs. The argument here is that the Europol JPSG represents a genuinely new form of interparliamentary cooperation within the EU, based on an innovative model of joint parliamentary scrutiny. This model need not be confined to the scrutiny of Europol or even the policy field of Justice and Home Affairs, but could serve as a template for the parliamentary oversight of other agencies and policy fields. It is a genuine innovation in the EU's system of multilevel parliamentary democracy (Cooper 2013).

The paper is structured as follows. It begins (Section 2) with a discussion of the meaning of 'joint parliamentary scrutiny' that emphasizes the distinctions between parliamentary scrutiny and parliamentary control, and between joint scrutiny and dual scrutiny. With these distinctions in mind, it continues (Section 3) with a historical overview of how the debate over the parliamentary scrutiny of Europol has developed over time, from the moment of Europol's creation in 1999 up to the passage of the Europol Regulation in 2016. Next (Section 4) it describes the process that brought the JPSG into being, detailing the consultations that led to the establishment of the parameters for the JPSG at the EU Speakers Conference in Bratislava in April 2017, up to the final adoption of its Rules of Procedure at the second meeting of the JPSG in Sofia in March 2018. This is followed by a close comparison (Section 5) of the Europol JPSG to the three major IPCs. It is argued that while there are a number of structural similarities, the Europol JPSG is a qualitatively different kind of interparliamentary body, with an explicit mandate to scrutinize and a specific object of scrutiny. In addition, it has a number of attributes each of which gives it stronger powers of scrutiny than those of the three IPCs. It has a stronger legal basis, more restrictive membership and participation rules, greater continuity of membership, the power to summon responsible EU officials, stronger access to documents, a non-voting seat on the executive body it oversees (the Europol Management Board), and an explicit right to ask oral and written questions. The paper continues with a brief note (Section 6) on the likely relationship between the post-Brexit UK parliament and 
the Europol JPSG. In conclusion (Section 7), the paper explores whether the Europol JPSG could serve as a template for other institutions of joint parliamentary scrutiny.

\section{What is Joint Parliamentary Scrutiny?}

It will be argued below that what sets the Europol JPSG apart from the three IPCs is that it has an explicit mandate to conduct 'joint parliamentary scrutiny' of an EU agency. But what does this mean, exactly? To explain, we must have a clear definition of 'parliamentary scrutiny,' which here is synonymous with 'parliamentary oversight' but very different from 'parliamentary control.' After that we must have an understanding of 'joint scrutiny,' as distinct from 'dual scrutiny.'

Parliamentary scrutiny may be defined as the actions taken by a parliamentary body when monitoring the activities of an executive authority within a political system. This deliberately loose definition employs generic terms - 'parliamentary body' rather than 'parliament,' 'executive authority' rather than 'government,' 'political system' rather than 'state' - in order to make them applicable not only to domestic parliaments but also to inter-parliamentary bodies within an international organization such as the EU. By this definition the pre-1979 EP, which was not yet a proper 'parliament' as it was not directly elected and lacked substantial legislative power, nevertheless engaged in scrutiny activities vis-à-vis the European Commission that deserved the label 'parliamentary scrutiny.' Whereas some scholars define 'parliamentary scrutiny' more narrowly, this definition is deliberately broad in that it includes all actions taken by a parliamentary body in the course of monitoring all aspects and phases of the executive authority's activities, whether legislative or non-legislative, whether it involves policy-formulation or policyimplementation, or whether or not it involves public expenditure. ${ }^{\mathrm{I}}$

Probably the single most important scrutiny tool wielded by a parliamentary body is its right to put a question to the executive authority and, under normal circumstances, receive an answer. Such questions may be intended simply to extract information, but quite often their true purpose is to make a comment regarding a current policy issue. Parliamentary questions may be written or oral. Written questions, often submitted by rank-and-file backbench MPs, will generally receive an answer in writing; oral questions may be put directly to the representative of the executive, such as a government minister, during a 
parliamentary session. Often this representative will appear in the parliament, either in plenary session or before a committee, to make a policy statement followed by questions and debate, in which parliamentarians may ask about and/or state their views on the policy. In addition, the parliamentary body may pass a non-binding resolution in order to communicate its opinion to the executive body. Or it may issue a more formal report, a written document that investigates a policy question in greater depth, but the ultimate purpose of which is to exert influence over the executive authority.

Parliamentary control, by contrast, is the power to appoint, censure or remove the executive; whereas some analysts consider this to be an aspect of parliamentary scrutiny, here, following Wouters and Raube (2012), scrutiny and control are treated as two separate functions. Parliamentary scrutiny is the power to monitor the actions of the executive while it is in office; parliamentary control is the power to determine whether the executive authority holds office at all. In general, the tools of parliamentary control are 'hard' (e.g. votes of investiture, votes of confidence) whereas the tools of parliamentary scrutiny are 'soft' (e.g. questions and debates, resolutions). Often there is a close relation between the two, insofar as the parliament's power of scrutiny may be strengthened by the fact that it holds in reserve the power to sanction the executive. However, these two functions are separable, and they do not always coincide. A parliamentary body may exercise a scrutiny function even if it lacks a control function, such as is frequently the case for the upper house within a bicameral parliamentary system. In the same way, the inter-parliamentary bodies of the EU - including the three IPCs and the Europol JPSG - may conduct parliamentary scrutiny vis-à-vis EU executive authorities even though they lack powers of control over them. ${ }^{\text {II }}$

It should be stated that the scrutiny function of any inter-parliamentary body vis-à-vis the EU executive is only supplemental to that performed by the EP and, to a lesser extent, individual national parliaments. Within the EU, the function of both parliamentary control and scrutiny is exercised mainly by the EP. Certainly, the function of control - the power to appoint, censure or remove the executive - is exercised largely by the EP, along with the Council and the European Council (Corbett et al. 2011). In addition, the EP is also by far the dominant parliamentary body in terms of the exercise of scrutiny of the EU executive, for which it has a broad array of scrutiny tools at its disposal - written questions, oral questions and debates, resolutions and reports - which it uses extensively. National 
parliaments, in contrast to the EP, have no direct role in the control of the executive authority of the EU, except insofar as they control their own governments and oversee their actions within the Council and the European Council. On an individual basis, national parliaments' direct scrutiny of the EU executive is limited. Aside from the occasional visit of EU officials to national parliaments, their interaction is largely confined to written correspondence with the Commission: they may raise specific subsidiarity-based objections to EU legislative proposals through the Early Warning Mechanism (Cooper 2012, 2017b), or other, more broad-based concerns through the 'political dialogue' (Rasmussen and Dionigi 2018).

What, then, is 'joint scrutiny'? A system of joint parliamentary scrutiny is one in which two or more parliaments together monitor the actions of an executive authority. In the EU, this is when the EP and national parliaments together scrutinize the actions of an executive authority of the EU. This may be contrasted with a system of 'dual parliamentary scrutiny' characterized by a division of labour between the scrutiny function of various parliaments, in which the EP oversees the EU executive and, separately, national parliaments oversee their respective national governments. The role of an inter-parliamentary body is quite different within these two scrutiny systems. In the former, the inter-parliamentary body has a direct scrutiny function in that it is the instrument through which participating parliaments directly scrutinize the executive, whereas in the latter its scrutiny function is indirect, in that it merely a forum in which the various parliaments can exchange information and best practices to enable them to carry out their separate scrutiny functions. In broad terms, in a system of joint scrutiny the inter-parliamentary body is an oversight body, whereas in a system of dual scrutiny it is a discussion forum (Cooper 2019 (forthcoming)).

This distinction between joint and dual scrutiny helps to explain the qualitative difference between the Europol JPSG and the three IPCs. Only the Europol JPSG is explicitly mandated and deliberately designed to be an oversight body, whose express purpose is joint parliamentary scrutiny. The three IPCs do not have an explicit scrutiny mandate; instead, their purpose, as set out in their respective Rules of Procedure, is generally to facilitate the exchange of information and best practices in keeping with a system of dual, rather than joint, scrutiny. ${ }^{\text {III }}$ In reality, the role of the IPCs is ambiguous in this regard, in that they all to varying degrees function as oversight bodies as well as 
discussion forums. ${ }^{\text {IV }}$ But as will be seen below, the Europol JPSG differs from these in that it has an explicit mandate to scrutinize.

\section{The Question of the Parliamentary Scrutiny of Europol, 1999-2016}

The Treaty of Lisbon identifies the policy field of Justice and Home Affairs (JHA) as one in which national parliaments ought to be particularly involved. Arguably there is a stronger Treaty basis for national parliaments to have an oversight role in JHA than in foreign and security policy or economic governance, the other specific policy fields for which there are IPCs. The Treaty of Lisbon states that national parliaments have both a general role overseeing the whole policy field, and a specific oversight role in relation to two agencies - Europol and Eurojust. One of the ways national parliaments contribute to the 'good functioning of the Union' is in part by 'taking part, within the framework of the area of freedom, security and justice, in the evaluation mechanisms for the implementation of the Union policies in that area', and, more specifically, 'through being involved in the political monitoring of Europol and the evaluation of Eurojust's activities' (Article 12(c) TEU). Europol and Eurojust are the only two EU agencies with an explicit Treaty basis under the Treaty of Lisbon (Rijpma 2014: 64). More generally, the EU Treaty singles out JHA as a policy field subject to enhanced scrutiny under the Early Warning Mechanism, requiring that national parliaments 'ensure' that new proposals in this area are compliant with subsidiarity, and the voting threshold for a 'yellow card' is lowered from one-third to one quarter for EU legislative proposals in the fields of police cooperation and judicial cooperation in criminal matters (Van Keulen 2014: 18-19).

Europol was established in 1999 as an international organization under the EU's 'Third Pillar', subject to very limited oversight from the EP and only indirect oversight from national parliaments, via their government ministers in the Council. While the EP has long sought greater oversight powers vis-à-vis Europol, there have also been various proposals for some form of joint scrutiny involving national parliaments. For example, in 2001 an interparliamentary conference held in the Hague (the city where the headquarters of Europol are located) proposed the creation of 'Parlopol,' a network for informationsharing between national parliaments and the EP to help facilitate oversight of Europol (Fijnaut 2002); and in 2002, the Commission suggested the creation of a joint supervisory 
committee in relation to Europol, to be made up both of members of national parliaments and MEPs (Ruiz de Garibay 2013: 89-90). The Treaty of Lisbon, which entered into force in December 2009, made Europol subject to regulation in accordance with the ordinary legislative procedure (i.e. co-decision): the EP and the Council 'shall determine Europol's structure, operation, field of action and tasks', including 'the procedures for scrutiny of Europol's activities by the European Parliament, together with national Parliaments' (Art. 88 TFEU). In anticipation of the Treaty of Lisbon entering into force, Europol was made an EU agency by a Council Decision of 2009. This decision actually reduced the influence of national parliaments over Europol, because it removed their powers of budgetary control and ratification; previously, any amendment to the Europol Convention had to be ratified by national parliaments - a process which took, on average, five years (Ruiz de Garibay 2013: 92). As an EU agency, Europol would henceforth be financed from the EU budget and governed by ordinary EU legislation.

Around this time there were exploratory discussions about what form the parliamentary scrutiny of Europol and Eurojust should take. In 2009, COSAC canvassed the opinions of national parliaments on this question, and reported that there was a variety of views but no real consensus, with some seeing COSAC itself as a possible venue, others seeing it as a matter for JHA committees, and others reluctant to create a new interparliamentary forum. ${ }^{\mathrm{V}}$ In 2010, the Commission issued a consultative document which proposed the setting up of a 'permanent joint or interparliamentary forum' for the scrutiny of Europol. ${ }^{\mathrm{VI}}$ There was further discussion of the question at the meeting of the EU Speakers Conference in Brussels in April 2011, led by Per Westerberg, speaker of the Swedish Riksdag. ${ }^{\text {VII }}$ The EP, for its part, periodically hosted Interparliamentary Committee Meetings (ICMs) on this and related topics in order to establish the practice of interparliamentary cooperation regarding Europol. Even so, plans for the JPSG only began to take shape after the Commission formally proposed the Europol regulation in 2013. In the meantime, two new IPCs were created, in the fields of foreign and security policy (the CFSP-CDSP Conference) in 2012 and EU economic governance (SECG Conference) in 2013, even as the Treaty mandate to create an interparliamentary mechanism to oversee Europol's activities lay dormant for years.

In March 2013, the Commission proposed the Europol Regulation, which would finally bring the agency into line with the Treaty of Lisbon. The proposal stated that Europol's 
activities would be subject to 'parliamentary scrutiny by the European parliament, together

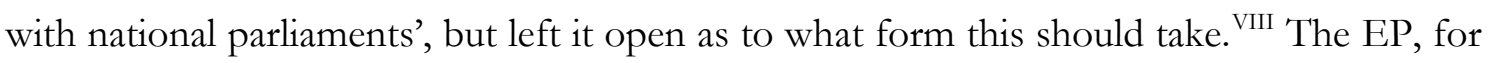
its part, responded with very specific proposals of its own in February 2014. In its amendments to the draft Regulation, the EP proposed the creation of a specialized body to be called the Joint Parliamentary Scrutiny Group (JPSG), made up of the all sixty MEPs in the EP's Justice and Home Affairs (LIBE) Committee in addition to two members from each national parliament, drawn from the relevant committees. ${ }^{\text {IX }}$ This body would exercise something close to a traditional parliamentary oversight function with respect to Europol, in that executive officials would appear before it at its request, and key documents related to the agency's activities and performance would be presented and debated. It would review the appointment (and re-appointment) of the Executive Director of Europol, and hold hearings with the Chairperson of the Europol Management Board, Commission representatives, the European Data Protection Supervisor, and other relevant officials.

This issue was discussed at the EU Speakers Conference in Vilnius in April 2014. The Speaker of the Italian Camera dei Deputati proposed that the EU Speakers Conference should endorse the 'prompt adoption' of the Europol Regulation, including the EP's proposed amendments with respect to the JPSG. However, some participants resisted this proposal in part on substantive grounds - seeing the JPSG as proposed by the EP as little more than an adjunct of the LIBE committee - but also on procedural grounds, saying that any new mechanism should be established by the parliaments themselves, rather than through the EU legislative process in which national parliaments are not direct participants. A very different proposal was put forward by Eva Kopacz, Speaker of the Polish Sejm, with the support of the Polish Senate, the Irish Senate and the Hungarian Parliament. The speakers of these chambers proposed the creation of a full-blown interparliamentary conference for the whole policy field of JHA, including scrutiny of the activities of Europol and Eurojust. The new IPC would be modelled on the formula of the CFSP-CSDP and SECG Conferences, in that it would replace existing meetings of chairpersons of relevant committees (interior/ home affairs), meet twice a year and be co-hosted and co-presided over by the EP and the Presidency Parliament. This new body, it was suggested, could also exercise oversight over the European Public Prosecutor's Office, whenever it came into being. However, the idea of a new interparliamentary conference was rejected as unnecessary by the EP representative at the meeting (Cooper 2017a: 233). 
Legislative negotiations continued between the EP and the Council, which reached an agreement on the Europol regulation in late November 2015; it was adopted in May 2016. The Regulation endorsed the establishment of a JPSG, but left it to the EU Speakers Conference and the JPSG itself to decide how the body should be established and structured.

\section{The Establishment of the Europol JPSG: 2016-2018}

The Europol Regulation was formally adopted on 11 May 2016 and was set to come into force on 1 May 2017. The regulation stated that scrutiny of Europol's activities would be carried out by a specialized JPSG, but it did not specify the structure of this body. Rather, it stated that the organization and the Rules of Procedure of the JPSG would be 'determined together by the European Parliament and the national parliaments in accordance with Article 9 of Protocol No 1' of the Treaty of Lisbon. Article 9 merely states, under the heading of 'interparliamentary cooperation,' that

The European Parliament and national Parliaments shall together determine the organisation and promotion of effective and regular interparliamentary cooperation within the Union.

What this meant in practice was that decisions regarding the organizational parameters for the JPSG would be made by the EU Speakers Conference (EUSC). While in the early years after the Treaty of Lisbon entered into force there was a debate over whether another interparliamentary body - e.g. COSAC - should assume this organizational task (Casalena et al. 2013, Esposito 2016), the EUSC prevailed, as seen in the fact that it effectively set the parameters for the CFSP-CSDP Conference (in 2012) and the SECG Conference (in 2013). Yet determining the organization of the JPSG presented a logistical challenge for the EUSC, which only meets once a year, because there was less than a year between the passage of the law (11 May 2016) and its entry into force (1 May 2017). Nevertheless, the EUSC largely succeeded, by instigating a consultative process delegated to a small group of parliaments (the troika), which eventually yielded a compromise text.

The EUSC customarily takes place in spring, hosted and chaired by the parliament of the member state that held the Council presidency in the previous autumn. The 2016 
meeting took place in Luxembourg on 22-24 May, just days after the passage of the Europol Regulation. At that meeting, the EUSC established a Working Group that consisted of the EUSC troika - composed of the parliaments of Luxembourg, Slovakia, and Estonia, and the European Parliament ${ }^{\mathrm{x}}$ - to consider possible scrutiny mechanisms and consult with all the EU parliaments/chambers in order to prepare a preliminary draft. The Troika Working Group produced a first draft in November 2016, which was discussed at an interparliamentary committee meeting (ICM) hosted by the LIBE committee in Brussels on 28 November 2016. In light of the discussions at that meeting, the Troika Working Group produced a second draft in December 2016. Numerous parliaments proposed further amendments to this second draft, which was discussed on 20-21 February 2017 at the meeting of the Secretaries-General of the EU parliaments - a group that meets annually prior to, and in preparation for, the annual meeting of the EUSC. Finally, the Slovak Parliament put forward its own 'presidency compromise' on 11 April, which provided the basis for the agreement at the 2017 EUSC meeting in Bratislava on 23-24 April. The final agreement regarding the modalities for the JPSG was included as an Annex to the Bratislava Conclusions.

The Working Group consultation on the modalities for the JPSG was an orderly process, more systematic and less contentious than the processes that had recently led to the creation of the CFSP-CSDP Conference and the SECG Conference (Herranz-Surrallés 2014, Cooper 2016a). In September 2017, the Working Group surveyed the opinions of the EU parliaments by having them fill out an online multiple-choice questionnaire eliciting their preferences regarding three modalities for the JPSG which were (1) its membership, (2) its numerical composition, and (3) the frequency, location and chairing and of its meetings. There was also an open-ended question looking for best practices in the parliamentary scrutiny of law enforcement at the national level. This survey received responses from 34 parliaments/chambers representing 25 member states and the EP.

Overall, the results were indecisive. Regarding (1) who should be members of the JPSG, opinion was split over whether it should be chairs $(6 \%)$ or members $(40 \%)$ of the relevant committees, persons selected individually by each parliament (31\%) or other $(23 \%)$. Concerning (2) the numerical composition of the JPSG, there was little support for any of the five options based on existing models of parliamentary meetings within EU-28, including the 42-member EUSC (4\%), a 172-member ICM (4\%), the 174-member COSAC 
Plenary $(12 \%)$, the 184 -member CFSP-CSDP Conference $(6 \%)$ or the unspecified number (approx. 200 members) of the SECG Conference (14\%); rather, the large majority of respondents $(60 \%)$ opted for none of these, instead preferring that the JPSG should have a new, yet-to-be-determined format. On (3) the question of the frequency, location and chairing of its meetings, opinion was also split over whether the JPSG should have one regular annual meeting in the EP, jointly chaired by the Presidency Parliament (PP) and the EP $(22 \%)$, two jointly-chaired meetings per year, one in the EP and one in the PP $(36 \%)$ two meetings per year hosted and chaired by the PP (20\%), or other (22\%). However, despite these indecisive results, the survey was a useful exercise in that it helped parliaments to eventually come to a consensus - as was the case, for example, regarding the frequency of meetings (two per year), as seen below.

Based on the results received in this consultation, the Troika Working Group produced a draft proposal setting out the following modalities for the JPSG: (1) its membership should be selected individually by each parliament/chamber, bearing in mind the need for substantive expertise or relevant committee membership; (2) the JPSG should be composed of 2 members per national parliament (one per chamber in bicameral parliaments) and six 6 MEPs, for a total of 62 members in EU-28; and (3) it should meet regularly once per year in the EP, co-chaired by the EP and the PP, with the possibility that an additional extraordinary meeting could be held in the PP if the co-chairs agree.

This draft proposal was debated at the ICM hosted by the LIBE committee in November 2016. Much of the debate, in particular concerning the second and third questions, raised the contentious question of whether the EP should enjoy an equal or a special status vis-à-vis national parliaments, an issue that had hindered the establishment of previous IPCs (Herranz-Surrales 2014; Cooper 2016a). Some national parliament representatives complained that two members per national parliament was too few, in particular because it only allowed for one representative per chamber in bicameral systems, making no allowance for party diversity. Many others argued that there should be at least two meetings per year, pointing out, rightly, that the majority of respondents to the survey had expressed this preference.

In light of this debate, the Troika Working Group produced a new draft text in December 2016 proposing a slightly larger JPSG with two members from each national parliament and ten from the EP, for a total of 66 members in EU-28, which would meet 
twice per year, in the PP in the first half and in the EP in the second half of a given year. (The proposal to alternate meetings between the PP and the EP, which was eventually adopted, was similar to the arrangement for the SECG Conference, in which the EP and the PP respectively host the meetings in the first and second halves of the year.)

Table 1. Comparison of Various Plans for Constitution, Frequency, Location of JPSG

\begin{tabular}{|l|c|c|c|c|c|}
\hline & MPs/ NP & MEPs & Total & Frequency & Location \\
\hline EP Amendments Feb. 2014 & 2 & 60 & 116 & $1 /$ yr. & EP \\
\hline Troika Working Group Nov. 2016 & 2 & 6 & 62 & $1 /$ yr. & EP \\
\hline Troika Working Group Dec. 2016 & 2 & 10 & 66 & $2 /$ yr. & PP1, EP2 \\
\hline EUSC Conclusions April 2017 & 4 & 16 & 128 & $2 /$ yr. & PP1, EP2 \\
\hline
\end{tabular}

This draft text received a number of further comments and suggested amendments. Eventually, there was a final agreement on a text that was included as an Annex to the EUSC Bratislava Conclusions. This endorsed a much larger JPSG, with four members from each national parliament and 16 from the EP, making for a total of 128 in EU-28; this body would meet twice per year in the PP (first half) and the EP (second half). In addition, extraordinary meetings could be convened upon the agreement of the PP and the $\mathrm{EP}$, or if requested by one third of the parliaments/chambers (i.e. even without the agreement of the EP).

It was commonly understood that the EUSC would establish the 'modalities' for the JPSG, but it would be up to the JPSG itself to establish its own Rules of Procedure. Thus it was that the Bratislava Conclusions settled many of the basic organizational questions regarding the JPSG - i.e. who would meet and where and when would they do so - but left many of the procedural 'what' and 'how' questions unanswered, such as 'What does it do?' and 'How is it going to work?' Many of these questions had been raised previously, but they came to the fore in particular after the Bratislava Conclusions had settled the modalities for the JPSG.

\section{Debate and Adoption of the Rules of Procedure, September 2017-March 2018}

The first, 'constituent' meeting of the Europol JPSG took place in October 2017 in the EP in Brussels, which was co-chaired by the EP and the Estonian parliament. Prior to the first meeting, in September 2017, the co-chairs produced a draft Rules of Procedure as a basis for further discussions and circulated it to all the national parliaments, many of which 
submitted amendments to the draft text - most notably, the German Bundestag (see below). Among the most important points discussed were: the status of the Troika and the Secretariat, the meaning of consensus 'in principle,' delegates' speaking time, oral and written questions (and replies), language interpretation (and costs), the reporting tasks of the JPSG representative on the Management Board, the status of subgroups, and the 'Danish question' - i.e. whether the parliament of an EU member state that is not a member of Europol may participate in the JPSG. The co-chairs of the constituent meeting, Claude Moraes, Chair of the LIBE Committee of the EP, and Raivo Aeg of the Legal Affairs Committee of the Estonian Parliament, strove to find a consensus. Oral agreement was in fact reached on most of these issues, but a few remained unresolved, and so the meeting ended without the adoption of the Rules of Procedure. It was feared that the JPSG could go through a similar ordeal as the SECG Conference, which had not adopted its Rules of Procedure until its fifth meeting, after more than two years of debate (Cooper 2017a: 240-243). But such fears proved unfounded, and the Rules of Procedure were adopted at the second meeting of the Europol JPSG in Sofia in March 2018.

Space does not permit the description here of all the varying positions of the national parliaments in these debates, but one in particular stands out. The German Bundestag was the parliamentary chamber that proposed the greatest number of amendments to this draft, and most of these were intended to increase the Europol JPSG's capacity to conduct effective scrutiny. The Bundestag proposed to amend the draft with the addition of wholly new provisions that would mandate the creation of a Presidency Troika and a Secretariat for the JPSG, and codify the option of creating subgroups, an explicit right to ask questions and to receive forwarded documents, and to revise its Rules of Procedure by absolute majority rather than consensus; it also proposed amendments that would strengthen existing provisions in the draft with respect to the JPSG's access to top EU officials and its ability to adopt conclusions by a decision rule other than consensus. The robustness of this set of proposals is notable because the Bundestag had taken a very different approach the last time an inter-parliamentary body was established. During the extensive debate over the Rules of Procedure for the SECG Conference between 20132015, the Bundestag had maintained that this new IPC should be no more than a discussion forum. For example, the Bundestag argued that the SECG Conference should not adopt conclusions at all: 
The German delegation regards the Conference as a forum for parliaments to share views and experience. The German delegation is therefore opposed to Conclusions which could be viewed as a political statement.XI

Why, then, did if take a dramatically different approach in the case of the JPSG? The simple explanation from the Bundestag is that the JPSG is different from the IPCs: under the terms of the treaty and the new Europol Regulation,

the European Parliament and national parliaments are to exercise joint oversight of a European executive authority for the first time. Interparliamentary cooperation in permanent bodies has bitherto been confined to exchanges of best practice. Article 51(1) of the new Europol Regulation goes much further by laying the foundations for permanent interparliamentary scrutiny of Europol (emphasis added). XII

These interventions from the parliament of the EU's largest member state were evidently very influential, as many were incorporated into the final text of the legislation.

One final issue which vexed the JPSG was the 'Danish question' - i.e. should the parliament of an EU member state which does not apply the Europol Regulation be a full member of the JPSG? Some parliaments, in particular the EP, took a hard line on this question, insisting that because the Danish populace voted against participating in Europol (in a December 2015 referendum) then it must categorically be excluded from the JPSG. The Danish parliament, for its part, argued (correctly) that it is unprecedented for an EU member state's parliament to be excluded from EU interparliamentary cooperation, pointing out that even the parliaments of non-signatories of the Fiscal Compact Treaty (TSCG) - Croatia, Czech Republic, and the UK - participated in the SECG Conference as full members (Cooper 2017c: 665-669). Interestingly, the Europol JPSG delegation from the LIBE committee requested an opinion from the EP legal service regarding the participation of the Danish parliament in the JPSG. The legal service produced a 'nonpaper' which concluded that the law does not provide a determinate answer:

- The issue is not comprehensively envisaged or legislated for by the Treaties nor by the Europol Regulation; 
- There is an obligation on all actors to act in good faith, and in line with the logic of the Treaties, and in line with the purpose of Article 88 TFEU and the Europol Regulation but there is no black-letter authority that absolutely rules in or rules out the full participation of the Danish Parliament in the JPSG. XIII

The implication of this opinion is that the participation of the Danish parliament is a political decision to be made by the JPSG itself. Eventually, a compromise was reached at the second meeting of the JPSG, which adopted the Rules of Procedure that effectively excluded Denmark, but also agreed to create a working group within the JPSG to study the question of Danish participation. This working group was scheduled to meet during the third meeting of the Europol JPSG in Brussels on 24-25 September 2018; at the time of writing no decision had been made.

\section{Comparing the JPSG with the Three IPCs: Stronger Powers of Scrutiny}

At first glance, the JPSG has many structural attributes that make it similar to the three major IPCs (see Table 2). Each of the four is a large, twice-yearly meeting of members of EU national parliaments and the EP, that is chaired or co-chaired by the Presidency Parliament (PP) as part of a series of events known as the Parliamentary Dimension of the Council Presidency (Cooper 2017a: 243-245). The participants are usually - but not necessarily - members of the relevant sectoral committee for the policy field under discussion at the meeting, i.e. EU affairs, foreign and defense policy, finance and economic policy, or justice and home affairs. In organizational terms, there is a certain variation among the four; in some respects the JPSG is an outlier, but not in a way that makes it qualitatively from the IPCs. For example, while there was initial discussion about making the JPSG dramatically smaller than the IPCs (about one-third the size) it has ended up being only somewhat smaller (about two-thirds). Another example is the role of the EP, which enjoys a special status in all four interparliamentary bodies, but to varying degrees. Of the four, the EP probably has greatest influence within the JPSG: not only does the EP host of one of the two yearly meetings of the JPSG (like in the SECG Conference) but it is co-chair of both (including the one held in the PP), and MEPs are numerically over- 
represented within it vis-à-vis national MPs (16 to 4) to a greater extent than in other IPCs (e.g. 16 to 6 in the CFSP-CSDP Conference). ${ }^{\mathrm{XIV}}$

Table 2: Comparing the JPSG with the Three Major Interparliamentary Conferences (IPCs)

\begin{tabular}{|c|c|c|c|c|}
\hline $\begin{array}{l}\text { Inter- } \\
\text { Parliamentary } \\
\text { Body }\end{array}$ & COSAC Plenary & $\begin{array}{l}\text { CFSP-CSDP } \\
\text { Conference }\end{array}$ & $\begin{array}{l}\text { SECG } \\
\text { Conference }\end{array}$ & JPSG \\
\hline Year established & 1989 & 2012 & 2013 & 2017 \\
\hline $\begin{array}{l}\text { Parliamentary } \\
\text { Committee(s) }\end{array}$ & European Affairs & $\begin{array}{l}\text { Foreign Affairs, } \\
\text { Defense }\end{array}$ & $\begin{array}{l}\text { Finance/ Budget, } \\
\text { Economics }\end{array}$ & $\begin{array}{l}\text { Justice and Home } \\
\text { Affairs }\end{array}$ \\
\hline Legal Basis & $\begin{array}{lr}\text { Amsterdam } & \text { Protocol; } \\
\text { Treaty of } & \text { Lisbon: } \\
\text { Protocol 1 } & \end{array}$ & $\begin{array}{l}\text { Treaty } \\
\text { Lisbon: } \\
\text { Protocol } 1\end{array}$ & $\begin{array}{l}\text { Treaty of Lisbon: } \\
\text { Protocol 1; } \\
\text { Article } 13 \text { TCSG }\end{array}$ & $\begin{array}{l}\text { Treaty of Lisbon: } \\
\text { Protocol 1, Art. 12(c) } \\
\text { TEU; Art. 88 TFEU; } \\
\text { Europol Regulation }\end{array}$ \\
\hline Delegation size & 6 per NP, 6 for EP & $\begin{array}{l}6 \text { per NP, } 16 \text { for } \\
\text { EP }\end{array}$ & Unspecified & 4 per NP, 16 for EP \\
\hline Location & PP Member State & $\begin{array}{l}\text { PP Member } \\
\text { State (may be } \\
\text { held in EP) }\end{array}$ & $\begin{array}{l}\text { Jan-June: EP } \\
\text { July-Dec: PP }\end{array}$ & $\begin{array}{l}\text { Jan-June: PP } \\
\text { July-Dec: EP }\end{array}$ \\
\hline Chair/ Co-Chairs & PP & $\begin{array}{l}\text { PP ('in close } \\
\text { cooperation' } \\
\text { with EP) }\end{array}$ & $\begin{array}{l}\text { Jan-June: EP and } \\
\text { PP co-chair } \\
\text { July-Dec: PP }\end{array}$ & $\begin{array}{l}\mathrm{EP} \text { and } \mathrm{PP} \text { co-chair } \\
\text { both meetings }\end{array}$ \\
\hline Troika & Strong & Weak & Weak & Strong \\
\hline Secretariat & $\begin{array}{l}\text { Provided by Troika, } \\
\text { w/ Perm. Member }\end{array}$ & Provided by PP & Provided by PP & Provided by Troika \\
\hline $\begin{array}{l}\text { Concluding } \\
\text { Document }\end{array}$ & $\begin{array}{ll}\text { Contribution } & \text { by } \\
\text { Consensus/QMV } & \end{array}$ & $\begin{array}{l}\text { Conclusions by } \\
\text { Consensus }\end{array}$ & Presidency Summary & $\begin{array}{l}\text { Summary Conclusions by } \\
\text { Consensus } \\
\text { principle' }\end{array}$ \\
\hline
\end{tabular}

In other measures of its institutional strength and autonomy, the JPSG could be said to occupy a middle ground among the IPCs. The RoP explicitly endows the JPSG with a Presidential Troika, and that this should in turn provide the Secretariat for the JPSG. These provisions regarding the Presidential Troika and the Secretariat are stronger than similar provisions for the CFSP-CSDP Conference and the SECG Conference, and as such give the JPSG a greater degree of institutional continuity, but weaker than the provisions for COSAC, whose Secretariat also includes a Permanent Member. In addition, the RoP also recognizes that the JPSG may debate and adopt Summary Conclusions by consensus in principle,' which may be used as an oversight tool with respect to Europol; this puts the JPSG on a par with the CFSP-CSDP Conference, which adopts Conclusions by consensus, in a weaker position than COSAC, which can adopt its Conclusions (formally, the 'Contribution') by QMV when consensus is unobtainable, but in a stronger position than the SECG Conference, which rarely adopts Conclusions (Cooper 2019 (forthcoming)). 
However, there are other aspects of the JPSG which clearly set it apart from the three IPCs. These are notable, in that they all point in the same direction: they all, to some extent, have the effect of increasing the effectiveness of the JPSG as an oversight body. Nine such contrasting attributes may be identified and enumerated here.

\subsection{A Mandate to Scrutinize}

Unlike the IPCs, the JPSG has a mandate specifically to conduct 'scrutiny' of Europol. This is evident not only in the fact that 'scrutiny' is in the body's name and that the treaty specifies that its purpose is 'scrutiny of Europol's activities.' The Europol Regulation states that the JPSG '...shall politically monitor Europol's activities in fulfilling its mission, including as regards the impact of those activities on the fundamental rights and freedoms of natural persons.' By contrast, the Rules of Procedure of the three IPCs do not state that their role is the direct scrutiny of EU institutions, but rather to provide a framework for 'the exchange of information and best practice(s).' They also state variously that the Conference's purpose is to enable 'a regular exchange of views' (COSAC RoP, Art. 1.1) and to 'contribute to ensuring democratic accountability' (SECG Conference RoP, Art. 2.1) in their respective policy fields.

The implication is that purpose of the IPCs is not direct scrutiny, but to assist individual parliaments in the separate performance of their scrutiny function, e.g. '.. to enable national Parliaments and the European Parliament to be fully informed when carrying out their respective roles in this policy area' (CFSP-CSDP RoP, Art. 1.1). By comparison, the JPSG has a very specific mandate to directly scrutinize that is set out not in its RoP but in the Europol Regulation. In the terms set out in Section 2, above, the JPSG exercises ‘joint scrutiny’ whereas the IPCs facilitate a system of 'dual scrutiny'.

\subsection{A More Focused Target of Scrutiny}

The JPSG is unlike the three IPCs in that the target of its scrutiny is an EU agency rather than a policy field. COSAC's remit is broadest, as it is a forum for the general discussion of EU affairs. But even the other two IPCs have a much wider remit than the JPSG, because they are concerned with the broad policy fields of foreign and security policy (CFSP-CSDP Conference) and economic governance (SECG Conference), and the outer edges of these policy fields are not well defined (Cooper 2017a: 234-235). There is 
not currently an IPC for the whole field of justice and home affairs, even though, as noted above, such a body was proposed at the EUSC in 2014. Rather, the only new interparliamentary body in this whole policy field is the JPSG, despite the fact that the EU treaties call for interparliamentary scrutiny of at least one other EU agency (Eurojust).

\subsection{Stronger Legal Basis}

As mentioned above, the JPSG enjoys a stronger legal basis than the three IPCs, both in terms of its basis in the EU treaties and in ordinary EU law. The three IPCs and the JPSG all rest on the Treaty of Lisbon's general recognition of interparliamentary cooperation' between national parliaments and the EP in Art. 12(f) TEU and Protocol 1, Art. 9 TEU (Casalena et al. 2013). The three IPCs also enjoy partial legal recognition and/or authorization in various other treaty provisions, including the Amsterdam Treaty's protocol on the role of national parliaments (COSAC), Protocol 1, Art. 10 TEU (COSAC, CFSP-CDSP Conference) and Article 13 of the TSCG (SECG Conference). By contrast, the Treaty of Lisbon specifies that national parliaments contribute to the good functioning of the EU by their involvement in the political monitoring of Europol (Art. 12(c) TEU), and authorizes that procedures be laid down in EU regulations whereby national parliaments and the EP can engage in scrutiny of Europol's activities (Art. 88 TFEU). It was under the latter provision that the Europol Regulation (2016/794) was passed, which specifically authorized/mandated the creation of the JPSG. Probably it is this latter provision, which gives the JPSG not just a vague treaty basis but a specific legal basis in ordinary EU legislation, that most sets the JPSG apart from the three IPCs.

\subsection{More Restrictive Membership and Participation Rules}

The JPSG has more restrictive rules of participation and membership than the three IPCs. It has already been noted that the size of the body is smaller (although not as small as earlier proposals would have had it), limited to four members per national parliament, as compared to six per NP in the COSAC plenary and the CFSP-CSDP Conference. In addition, the rules regarding which parliaments can participate are more restrictive. The parliaments of all EU member states (and the European Parliament) are full members of the three IPCs; ${ }^{\mathrm{XV}}$ members of parliaments of EU candidate countries have the right to attend as observers, while guests from other non-EU parliaments may also be invited to do 
so. ${ }^{\mathrm{XVI}}$ The RoP of the JPSG, by contrast, makes clear that full membership and participation is only possible for those EU member states 'applying the Europol Regulation' (JPSG RoP, Art. 2.1). The parliament of an EU member state not applying the Europol Regulation cannot send four members to the JPSG, nor can it act as co-chair of the JPSG when its government holds the Council presidency; in such circumstance, the previous Presidency Parliament must act as co-chair (Art. 3.1). This is the only instance of an EU member state parliament being formally excluded from full membership in an EU interparliamentary body; currently the only EU member state not applying the Europol Regulation, and therefore excluded by this rule, is Denmark. ${ }^{\text {XVII }}$ The RoP of the JPSG are also more restrictive with respect to observers: candidate countries do not have a right to attend in this capacity, but only 'observers from the list of EU Member States that have concluded an Agreement on Operational and Strategic Cooperation with Europol' (Art. 2.2). While many countries have concluded such agreements, only one EU member state has done so - Denmark. As for non-EU member states, the RoP state the following:

The JPSG may also decide to invite, on an ad hoc basis and for specific points on the agenda, observers from the list of international organisations or third countries with which Europol has concluded agreements.

Even in the case of third countries with an extremely close working relationship to Europol, such as Norway, their parliamentary representatives can only attend on an ad hoc, non-voting basis. Under the current rules, this will be also be the position of the postBrexit UK, once it has concluded an agreement with Europol.

\subsection{Continuity of Membership}

In order to fulfill its scrutiny function, the individual members of the JPSG should be experts in their field who attend on a regular basis. This would be an improvement on the IPCs, which are often attended by a somewhat haphazard collection of members from the participating parliaments - usually but not always from the relevant committees - who may or may not have participated in the last meeting. To this end, the RoP specifies: 
Members of the JPSG shall be selected individually by each Parliament/Chamber, bearing in mind the necessity to ensure substance matter expertise as well as long-term continuity. Where possible, members of the JPSG shall be nominated for the duration of their parliamentary mandate.

There is no equivalent requirement in the RoP of the three IPCs. Ultimately it is up to each parliament to decide, by its own rules, who it chooses to send as representatives to international fora; therefore it is difficult for an interparliamentary body to set uniform rules of participation. At most, the RoP can only set out guidelines in this regard. Even so, the idea here is that the individual members of the JPSG would have substance matter expertise and be nominated and serve for long periods of time - which, if successful, would greatly enhance the effectiveness of the JPSG as a scrutiny body and its members' sense of collective identity.

\subsection{Power to Summon Responsible EU Officials}

It is customary for the three IPCs to be attended and addressed by top EU officials. Normally each IPC will be attended by a representative of the Commission (typically, the Commissioner responsible for the policy field under discussion) and the Council (typically a senior minister of the member state holding the Council presidency) who will address the body and answer questions. However, sometimes for various reasons the officials in question will not attend or will send a video message; when this happens it annoys the assembled parliamentarians, who consider it of great importance that top EU officials appear before them in person. But according to their RoP, the IPCs can only request - not demand - their attendance. For example, the RoP of the CFSP-CSDP Conference merely state that the EU's High Representative for CFSP-CSDP 'shall be invited' to address the conference (Art. 2.3) and the RoP of the SECG Conference state that the 'representatives of EU Institutions' responsible for EU economic governance 'should be invited' to appear before it (Art. 4.2). By contrast, the RoP of the JPSG state unequivocally that the relevant EU officials (or their deputies) 'shall appear':

Pursuant to the Europol Regulation, and in particular Article 51, the Chairperson of the Management Board, the Executive Director or their Deputies, and the European Data Protection Supervisor (EDPS) shall appear before the JPSG at its request (Art 2.3). 
These rules were mostly respected at the first two meetings of the JPSG. The three key officials named above - the Chairperson of the Management Board, the Executive Director, and the EDPS - all appeared before the JPSG at its first meeting in October 2017. Appearing before the JPSG at its second meeting, in March 2018, were the Chairperson of the Management Board, the Executive Director, but the EDPS was absent and sent a video message (the deputy EDPS appeared in his place). While the rules do not require it, the relevant representatives of the Commission and the Council also frequently appear before the JPSG. At the first meeting the Council was represented by the Estonian minister of the interior, but the responsible Commissioner (Julian King, Commissioner for the Security Union) was absent, sending a video message instead. Attending the second meeting were the Bulgarian minister of the interior, for the Council, and the responsible Commissioner (Julian King).

\subsection{Access to Documents}

Another way that the JPSG differs from the three IPCs is that it has explicit rights regarding access to documents. While Protocol 1 of the Treaty of Lisbon entitles national parliaments to receive consultative, legislative and policy documents from the EU institutions, the IPCs as institutions have no such rights. The JPSG, by contrast, must receive from Europol a number of specific documents listed in the Europol regulation. These include 'threat assessments, strategic analyses and general situation reports related to Europol's objective as well as the results of studies and evaluations commissioned by Europol,' as well as documents concerning administrative arrangements and multiannual programming, the annual work programme and annual activity report, and the evaluation report drawn up by the Commission. Europol must transmit these to the JPSG 'for information purposes... taking into account the obligations of discretion and confidentiality' (Art. 51(3)). This list of documents is not exclusive; the JPSG may also request other relevant documents '....necessary for the fulfilment of its tasks relating to the political monitoring of Europol's activities' (Art. 51(4)).

\subsection{A Seat on the Management Board}

Another novel feature of the JPSG in comparison to the IPCs is that it can occupy a non-voting seat on the executive body that it is overseeing, i.e. the Management Board of 
Europol, which is otherwise made up of one representative of each member state and of the Commission. According to Article 5 of the RoP,

The JPSG shall appoint, from its full Members, a representative who will be entitled to attend, in accordance with Article 14 of the Europol Regulation and for a duration determined by the JPSG, meetings of the Management Board of Europol as a non-voting observer. The representative shall report back to the JPSG after each meeting of the Management Board on his/her main findings in writing.

While the RoP states that the JPSG representative will be 'entitled to attend' all such meetings - of which there are at least two per year - the language of the Europol regulation is more equivocal. It states that the Management Board '... may invite any person whose opinion may be relevant for the discussion, including, where appropriate, a representative of the JPSG, to attend its meeting as a non-voting observer' (Art. 14(4), emphasis added). However, even if it is still uncertain exactly what level of access the JPSG representative will have to Management Board meetings, it is nevertheless an important innovation in the parliamentary scrutiny of an executive body of the EU. ${ }^{\text {XVIII }}$

\subsection{The Right to Ask Oral and Written Questions}

It is a normal occurrence at IPCs that EU officials will address the meeting and take oral questions from the assembled parliamentarians. However, this is not a formal requirement and the encounter is often styled as a 'debate' or 'exchange of views.' The JPSG formalizes the requirement that EU officials must answer the questions put to them by its members. Crucially, it also adds the proviso that representatives of Europol must also answer written questions that are addressed to them outside the framework of the meeting itself:

Members of the JPSG may address both oral and written questions to Europol. Written questions may also be asked outside the meeting framework and independently of items listed on the agenda and shall be answered within an appropriate timeframe. [...] A further written reply can be requested in case the answer to an oral question is deemed insufficient.

This provision creates a mechanism for the oversight of Europol on an ongoing basis rather than merely during the twice-yearly meetings of the JPSG. This is important because 
the right of a parliamentary body to put questions to an executive authority and to receive an answer is arguably the most essential tool of parliamentary scrutiny.

\section{Brexit and the Europol JPSG}

The Europol regulation was negotiated and adopted prior to the UK's Brexit referendum, and it does not address the unforeseen circumstance of an EU member state becoming a 'third country.' The UK had enjoyed a unique outside-inside relationship with the AFSJ: in 2014 it exercised its block opt-out from police and criminal justice measures but selectively opted back in to many of them, including participation in Europol and Eurojust (Curtin 185). After the Brexit referendum, the UK government announced that it would opt in to the new Europol regulation and maintain its current access until it leaves the EU. However, the UK's future relationship with Europol after Brexit remains entirely unresolved: whereas the UK hopes to negotiate a new security treaty through which it will remain in Europol, the EU's chief negotiator, Michel Barnier, has remarked that it is a 'logical consequence' of Brexit that the UK must leave Europol. ${ }^{\mathrm{XIX}}$

The UK's prospects appear difficult when compared to the countries in the closest analogous situation, Norway and Denmark. As a 'third country,' Norway's position in Europol is limited in comparison to that of EU member states, and the limited access it does enjoy is conditional on its continued close association with the EU through Schengen and the EEA. By contrast, Denmark is an EU member state but it ceased to be a member of Europol after a referendum in December 2015; Denmark managed to negotiate a continued close association with Europol but it does not have full membership - it no longer has a voting seat on the Management Board, for example - and even the 'third country' access it enjoys is conditional on its continued EU membership, Schengen participation and recognition of ECJ jurisdiction (Curtin 187-193). By the same standard, it will be difficult for the UK to retain the level of access enjoyed by Denmark or even Norway, given that it is already outside Schengen and it has pledged to leave not only the EU but also the EEA and the jurisdiction of the ECJ.

The UK's level of access to the JPSG is analogous to and dependent on its access to Europol itself, and the positions of Denmark and Norway are instructive. Even though Denmark is a member state, under the current RoP it is excluded from full membership in 
the JPSG and is relegated to the status of a non-voting observer and cannot act as co-chair. Yet even this status is privileged in comparison to that of Norway because, as an EU member state with an Agreement on Operational and Strategic Cooperation, Denmark at least has an automatic right to attend, whereas Norway must be invited on an ad hoc basis. If the rules remain the same, the post-Brexit UK would be in the same position as Norway, needing to receive an invitation in order to attend. This would be similar to the COSAC plenary, which is routinely attended by observers from the Norwegian parliament after they routinely send a letter requesting an invitation (Cooper 2015: 116). It differs from the CFSP-CSDP conference, to which the Norwegian parliament has a right to send up to four observers - as will the UK parliament post-Brexit - because Norway is a European NATO member.

The likely exclusion of the UK from the JPSG is an unfortunate outcome, given the UK's extensive involvement in cross-border police cooperation; it is, for example, the second largest contributor to Europol information systems. ${ }^{\mathrm{xx}}$ Ironically, three of the top EU officials at the March 2018 meeting of the JPSG were British - Rob Wainwright, the Executive Director of Europol, Julian King, the Commissioner for the Security Union, and Claude Moraes who, as chair of the EP's LIBE committee, co-chaired the meeting. Wainwright left in April 2018 after nine years in the position; King and Moraes are set to leave their posts when Brexit occurs in early 2019.

After the referendum, the UK surrendered the influence it might have had over the formation of the JPSG. In July 2016, Theresa May removed the UK from holding the rotating Council presidency in late 2017, and Estonia took its place. This also meant that the UK parliament no longer acted as the chair of interparliamentary meetings (Presidency Parliament), resulting in two lost opportunities. First, the UK parliament was replaced by the Estonian parliament in the Troika working group (along with the EP and the parliaments of Luxembourg and Slovakia) which was leading the consultative process that set the modalities for the JPSG in the Bratislava conclusions. And second, it was the Estonian parliament rather than the UK parliament that co-chaired the first meeting of the JPSG in the fall of 2017 when the Rules of Procedure were first debated; if the UK had been the Presidency Parliament it is likely that the person acting as co-chair would have been Yvette Cooper, the Labour MP who is the chair of the Home Affairs Committee of 
the House of Commons, who would have been a forceful voice for the interests of the UK parliament.

\section{Conclusion}

The final adoption of the Rules of Procedure for the Europol JPSG at its second meeting in March 2018 was acclaimed as an historic moment. It is the first body of its kind, grounded in the EU treaty and mandated by EU law as an instrument through which the EP and national parliaments would together scrutinize the activities of an EU agency. It introduced the first formal mechanism of joint parliamentary scrutiny into modern EU politics (if one excludes the pre-1979 EP) and was thus an innovation in the EU system of multinational parliamentary democracy.

Even so, while the formal scrutiny powers of the Europol JPSG are in many ways considerably stronger than those of the IPCs, their effectiveness will ultimately depend on how they are used. The right to ask questions is the most basic tool of parliamentary oversight, but its effectiveness depends on what questions are asked (and aggressively followed up) and what answers are given: for example, the JPSG's role in the 'political monitoring' of Europol should not preclude its scrutiny of operational matters (Kreilinger 2017: 13). In addition, it remains to be seen whether the parliaments can forge a cooperative working relationship; it is a good sign that, even if it was previously less favourable in the case of the three IPCs, the EP is now positively disposed to joint parliamentary scrutiny as exercised by the JPSG over Europol.

The final question to ask is, can the model of the Europol JPSG be exported to other interparliamentary bodies to oversee different agencies and policy fields? Certainly the possibility of applying this template to other agencies in the area of Justice and Home Affairs should be explored, given that this is a sensitive policy field over which national parliaments will wish to continue to exercise scrutiny (Cooper 2017a). The most obvious candidate is Eurojust, the European agency for judicial cooperation in criminal matters, which is in many ways Europol's institutional 'twin,' as the two are given special recognition in the Treaty of Lisbon. Like Europol, Eurojust is expected to subject to some form of joint parliamentary scrutiny in that the EP and national parliaments are to be involved in 'the evaluation of Eurojust's activities.' However, early drafts of the Eurojust 
regulation, which has not yet been adopted, only foresaw a very minimal role for national parliaments, whose 'involvement' would be limited to receiving certain documents such as the Eurojust annual report, rather than some new mechanism of joint parliamentary scrutiny (Briere 2017; Gless and Wahl 2017). Other possible targets for joint parliamentary scrutiny could include the newly established European Public Prosecutor's Office (EPPO), which is closely related to Eurojust, or other agencies in the field of Justice and Home Affairs such as Frontex, the EU's border security agency. However, if such joint scrutiny bodies were to proliferate in this policy field, it might be suggested that they should consolidated into a full-blown IPC for the Justice and Home Affairs, as was proposed at the EU Speakers Conference in 2014. Another possibility is that, if the JPSG proves to be a success, it could provide a model for the three IPCs, prompting them to reorganize their efforts away from being discussion forums and more to being oversight bodies engaged in joint parliamentary scrutiny of the EU executive.

\footnotetext{
* DCU Brexit Institute, Dublin City University.

${ }^{\text {I }}$ For a comparison of different definitions of parliamentary oversight, and an exhaustive list of parliamentary oversight tools, see Pelizzo and Stapenhurst (2012).

II It is interesting to note that a previous draft of the Europol Regulation would actually have given the JPSG an element of parliamentary control - not just scrutiny - of the executive. The version of the legislation as amended by the EP in 2014 would have given the JPSG a say in, albeit not a veto over, the appointment/ approval of the Executive Director of Europol. It would have required that, in the case of a new appointment, candidates for the post of Executive Director appear before the JPSG at its request, and the same would apply to a sitting Executive Director whose term of office is to be extended. In addition, the Chairperson of the Management Board would have had to inform the JPSG before removing the Executive Director from office, as well as to the reasons for such a decision. However, these provisions were removed from the final version of the legislation, so that in the end the JPSG only received powers of scrutiny, not control, vis-à-vis Europol. European Parliament legislative resolution of 25 February 2014 on the proposal for a regulation of the European Parliament and of the Council on the European Union Agency for Law Enforcement Cooperation and Training (Europol) and repealing Decisions 2009/371/JHA and 2005/681/JHA (COM(2013)0173 - C7-0094/2013 - 2013/0091(COD)). 25/02/2014, Amendment 200 (Art. $53)$.

III The reasons for this are complicated, but it is due in part to the fact that the EP frequently fights the creation of any new inter-parliamentary body that could challenge its position as the pre-eminent parliamentary scrutiny body at the EU level, whereas national parliaments for their part take varying positions on this question (Cooper 2016b: 261-265). It is notable that the EP took a much more positive position in this case, advocating that the Europol JPSG should have substantial scrutiny powers (Kreilinger 2017).

IV For a comparative analysis of the three IPCs in this regard, see Cooper 2019 (forthcoming).

v COSAC Eleventh Bi-annual Report: Developments in European Union Procedures and Practices Relevant to Parliamentary Scrutiny, 11-12 May 2009, p.10-15.

VI Communication from the Commission to the European Parliament and the Council on the procedures for the scrutiny of Europol's activities by the European Parliament, together with national Parliaments, $\operatorname{COM}(2010) 776$ final, 17.12.2010. National parliaments' responses to this document are available at: <http://www.ipex.eu/IPEXL-WEB/dossier/document/COM20100776FIN.do >.

VII Some national parliaments submitted written contributions to this debate, which are available at: <http://www.ipex.eu/IPEXL-WEB/euspeakers/getspeakers.do?id=082dbcc530b1bef60130b64f909f0023 >. VIII Proposal for a Regulation of the European Parliament and of the Council on the European Union Agency
} 
for Law Enforcement Cooperation and Training (Europol) and repealing Decisions 2009/371/JHA and 2005/681/JHA (COM/2013/0173), 27/03/2013, Art. 53(2), p.51. National parliaments' responses to this document are available at: <http://www.ipex.eu/IPEXL-WEB/dossier/document/COM20130173.do>

IX European Parliament legislative resolution of 25 February 2014 on the proposal for a regulation of the European Parliament and of the Council on the European Union Agency for Law Enforcement Cooperation and Training (Europol) and repealing Decisions 2009/371/JHA and 2005/681/JHA (COM(2013)0173 - C70094/2013 - 2013/0091(COD)). 25/02/2014, Amendment 200 (Art. 53).

$\mathrm{x}$ Initially, the troika included the UK parliament, which was replaced by the Estonian parliament when the UK dropped out of the Council presidency rotation after the Brexit referendum of 23 June 2016. Conclusions of the EU Speakers Conference, Luxembourg, 22-24 May 2016, paras. 34 and 35. (See Section 6.)

XI Amendments of the German Delegation to the Rules of Procedure of the SECG Conference, 9 March 2015, p. 8.

XII Amendments of 26 September 2017 to the draft Rules of Procedure of 6 September 2017 for the Joint Parliamentary Scrutiny Group on Europol, 26 September 2017, p.1.

XIII Non-paper on the Draft Rules of Procedure of the Joint Parliamentary Scrutiny

Committee on Europol as regards participation of the Danish Parliament

XIV According to its rules, the CFSP-CSDP Conference may be held in the EP, but this has never happened.

xv Even the SECG Conference is open to all EU national parliaments, even though its treaty basis (Art. 13 TSCG) implied that only the 25 'contracting parties' should take part (Cooper 2017c: 665-669).

XVI Parliaments of European non-EU NATO member countries (e.g. Norway) can attend the CFSP-CSDP Conference as observers. This rule would also apply to the post-Brexit UK.

XVII As mentioned above, an agreement was reached to set up a working group to review the rules of participation, and so these are subject to change.

XVIII The Europol regulation also requires the Management Board to consult the JPSG regarding its multiannual programming (Art. 12(1)).

XIX Speech by Michel Barnier at the Berlin Security Conference, Berlin, 29 November 2017. Available at:

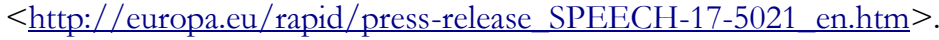

$\mathrm{xx}$ 'Europol head fears loss of UK influence after Brexit', BBC News, 31 January 2018, <https://www.bbc.com/news/uk-42874985>.

\section{References}

- Brière, Chloé 2018, 'Cooperation of Europol and Eurojust with External Partners in the Fight Against Crime: What are the Challenges Ahead?', DCU Brexit Institute Working Paper No. 1-2018.

- Casalena Pier Giorgio, Lupo Nicola and Fasone Cristina, 2013, 'Commentary on the Protocol No 1 Annexed to the Treaty of Lisbon', in Blanke Hermann-Josef and Mangiameli Stelio (eds), The Treaty on European Union (TEU). A Commentary, Springer, Heidelberg, 1529-1633.

- Cooper Ian, 2019 (forthcoming), 'The Inter-Parliamentary Conferences of the European Union: Discussion Forums or Oversight Bodies?' in Raube Kolja, Müftüler-Baç Meltem, and Wouters Jan (eds), Parliamentary Cooperation and Diplomacy in EU External Relations - An Essential Companion, Edward Elgar Publishing, Cheltenham.

- Cooper Ian, 2017a, 'The Emerging Order of Interparliamentary Cooperation in the Post-Lisbon EU', in Jancic Davor (ed), National Parliaments after the Lisbon Treaty and the Euro Crisis: Resilience or Resignation?, Oxford University Press, Oxford, 227-246.

- $\quad$ Cooper Ian, 2017b, 'Is the Early Warning Mechanism a legal or a political procedure? Three questions and a typology', in Jonsson Cornell Anna and Goldoni Marco (eds), National and Regional Parliaments in the EULegislative Procedure Post-Lisbon: The Impact of the Early Warning Mechanism, Hart Publishing, Oxford, 17-49.

- Cooper Ian, 2017c, 'A Separate Parliament for the Eurozone? Differentiated Representation, Brexit, and the Quandary of Exclusion', Parliamentary Affairs, LXX(4): 655-672.

- Cooper Ian, 2016a, 'The Politicization of Interparliamentary Relations in the EU: Constructing and Contesting the 'Article 13 Conference' on Economic Governance', Comparative European Politics, XIV(2): 196214. 
- Cooper Ian, 2016b, 'The Interparliamentary Conference on Stability, Economic Coordination and Governance (the "Article 13 Conference"),' in Lupo Nicola and Fasone Cristina (eds), Interparliamentary Cooperation in the Composite European Constitution, Hart Publishing, Oxford, 247-267.

- Cooper Ian, 2015, 'The Nordic Parliaments and the EU,' in Caroline Howard Grøn, Peter Nedergaard and Anders Wivel (eds), Still the other European Community? The Nordic Countries and the European Union, Routledge, Abingdon, 104-122.

- Cooper Ian, 2013, 'Bicameral or Tricameral? National Parliaments and Representative Democracy in the European Union,' Journal of European Integration, XXXV(5): 531-546.

- Cooper Ian, 2012, 'A 'Virtual Third Chamber' for the European Union? National Parliaments After the Treaty of Lisbon, West European Politics, XXXV(3): 441-465.

- $\quad$ Corbett Richard, Jacobs Francis and Shackleton Michael, 2011, The European Parliament, 8th ed., John Harper Publishing, London.

- Curtin Deirdre, 2017, 'Brexit and the EU Area of Freedom, Security and Justice: Bespoke Bits and Pieces', in Fabbrini Federico (ed), The Law and Politics of Brexit, OUP, Oxford, 182-200.

- Esposito Antonio, 2016, 'The Role of COSAC in EU Interparliamentary Cooperation: An (Endless) Quest for an Identity', in Lupo Nicola and Fasone Cristina (eds), Interparliamentary Cooperation in the Composite European Constitution, Hart Publishing, Oxford, 325-333.

- $\quad$ Fijnaut C.J.C.F., 2002, 'Europol and the parliaments of the member states of the European Union', in Dutch Parliament (ed), From Europol to Parlopol; interparliamentary conference on democratic control of Europol, Boom, Amsterdam, 15-19.

- $\quad$ Fromage Diane, 2017, 'The New Joint Parliamentary Scrutiny Group for Europol: Old Wine in New Bottles?' blog post available at: <http://eutarn.blogactiv.eu/2017/06/17/the-new-joint-parliamentaryscrutiny-group-for-europol-old-wine-in-new-bottles $>$.

- Gless Sabine and Wahl Thomas, 2017, 'A Comparison of the Evolution and Pace of Police and Judicial Cooperation in Criminal Matters: A Race Between Europol and Eurojust?', in Brière Chloé and Weyembergh Anne (eds), The Needed Balances in EU Criminal Law: Past Present and Future, Hart Publishing, Oxford, 339-354.

- Herranz-Surrallés Anna, 2014, 'The EU’s multilevel parliamentary (battle) field: Inter-parliamentary cooperation and conflict in foreign and security policy', West European Politics XXXVII(5): 957-975.

- Kreilinger Valentin, 2017, 'A Watchdog for Europe's Policemen: The Joint Parliamentary Scrutiny Group for Europol' (Policy Paper / Jacques Delors Institute), Jacques Delors Institute, Berlin. https://doi.org/10.13140/RG.2.2.33360.10244

- Pelizzo Riccardo and Stapenhurst Frederick, 2012, Parliamentary Oversight Tools: A Comparative Analysis, Routledge, London.

- $\quad$ Rasmussen Mette Buskjær and Dionigi Maja Kluger, 2018, 'National parliaments' use of the political dialogue: Institutional lobbyists, traditionalists or communicators?', Journal of Common Market Studies, LVI(5): 1108-1126.

- Rijpma Jorrit, 2014, 'Institutions and Agencies: Government and Governance after Lisbon', in Acosta Arcarazo Diego and Murphy Cian (eds), EU Security and Justice Law, Hart Publishing, Oxford, 54-76.

- Ruiz de Garibay Daniel, 2013, 'Coordination Practices in the Parliamentary Control of Justice and Home Affairs: The Case of Europol', in Crum Ben and Fossum John Erik (eds), Practices of Inter-Parliamentary Coordination in International Politics: The European Union and Beyond, European Consortium for Political Research Press, Colchester, 87-103.

- Van Keulen Mendeltje, 2014, 'New Parliamentary Practices in Justice and Home Affairs: Some Observations', in Holzhacker Ronald L and Luif Paul (eds), Freedom, Security and Justice in the European Union, Springer Verlag, New York, 18-19.

- Wouters Jan \& Raube Kolja, 2012, 'Seeking CSDP Accountability Through Interparliamentary Scrutiny', The International Spectator, XLVII(4): 149-163. 